\title{
FOREIGN BODY GRANULOMATA OF THE LUNGS DUE TO LIQUID PARAFFIN
}

\author{
BY \\ J. C. WAGNER, D. I. ADLER, AND D. N. FULLER \\ From the Department of Pathology, South African Institute for Medical Research, and the Thoracic Surgery Unit, \\ General Hospital, Johannesburg
}

(RECEIVED FOR PUBLICATION SEPTEMBER 20, 1954)

This paper is based on the clinical, operative, and pathological findings of five cases of liquid paraffin granulomata of the lung.

\section{HisTORICAL}

The recognition of oil granulomata of the lung followed the use of oils as a vehicle for medicaments and radio-opaque substances in diagnostic bronchography.

Rosenberg (1885) used menthol in olive oil for the treatment of tuberculous laryngitis. This treatment was fairly widely adopted. Following the discovery of the efficacy of chaulmoogra oil as a treatment for leprosy this oil was substituted for the menthol by Lukens (1922). They believed that medicated oils did not penetrate further than the larynx. This was disproved by GuieyssePellissier (1920), who showed, in rabbits, that olive oil injected into the larynx could be demonstrated in the alveoli within six hours. Corper and Freed (1922) showed that oil placed in the nasal cavity was also carried to the alveoli. Laughlen (1925) first described cases of lipoid pneumonia following the use of nose drops of which the base was liquid paraffin. Pinkerton (1927) described six cases in which he could trace the pathogenesis from a simple lipoid pneumonia to a discrete fibrotic oil granuloma.

Graef (1935) suggested that mineral oils gain entrance to the lungs by $(a)$ not irritating the surface of the pharyngeal mucosa and so not exciting a cough reflex; (b) the presence of mild anaesthetic substances in the mineral oil, such as menthol, enhancing the passage of the oil into the trachea; (c) a defect of the cilia in chronic respiratory infections; and $(d)$ loss of the cough reflex in weak and debilitated patients.

Ikeda (1937) distinguished between infantile and adult forms of lipoid pneumonia. The "infantile form " can occur in infants and the aged. This lesion, usually of a diffuse nature, is essentially an interstitial proliferative inflammation not infrequently combined with exudative pneumonia. The "adult type," usually localized, mostly occurs among older persons as a result of the habitual self-administration of oil in large amounts by mouth or intra-nasally over a long period, and occasionally also as a result oî direct intra-tracheal instillation. Ikeda pointed out the clinical and radiographical difficulty of distinguishing these " adult" lesions from other intrapulmonary lesions.

Stryker (1911) showed that liquid paraffin can be absorbed from the gut and demonstrated in the regional lymph glands. Daniel, Frazer, French, and Sammons (1953) suggested that a portion of the liquid paraffin taken by mouth is absorbed from the gut as fatty acids. It is possible that liquid paraffin in an emulsified form may be carried in the lymphatic ducts directly into the systemic venous circulation and thence to the lungs. Some of the cases of "paraffinoma" that have been described by previous authors may have had their origin in this way.

The intra-tracheal injection of radio-opaque substances in oil was first carried out in animals by Waters, Bayne-Jones, and Rowntree (1917). Some of these animals died of a proliferative bronchopneumonia in which the alveolar and bronchial epithelium was stated to be considerably hypertrophied. Sicard and Forestier (1922) used " lipiodol," which is iodized poppyseed oil, to demonstrate the bronchial tree in human subjects. Pinkerton (1928) after extensive investigation came to the conclusion that (1) mineral oil is quickly emulsified in the lungs and taken up by the alveolar phagocytes which fill the alveoli, producing a consolidation which is followed by fibrosis; (2) most vegetable oils produce practically no reaction in the lung even 
if retained for a long time; (3) animal oils produce oil granulomata; (4) the reaction of the lungs to an oil varies directly with the free fatty acid content of the oil; (5) poppyseed oil and sesame oil being almost inert are suitable for bronchography. This view was generally held until Brody (1943) first described an oil granuloma due to iodized poppyseed oil following bronchography. The granuloma occurred distal to a bronchial obstruction caused by a carcinoma. A further case of "lipiodol" granuloma due to poppyseed oil was reported by Fortner and Miles (1950). Cases of oil granulomata of the lung due to iodized poppyseed oil have been reviewed and investigated by Felton (1952). He examined 37 lung specimens from 34 patients, all of whom had had bronchograms with iodized poppyseed oil 46 to 1,404 days before operation. In 23 of the specimens residual poppyseed oil was demonstrated, and in six cases oil granulomata were found.

Similar granulomata have been found elsewhere in the body following the use of "lipiodol." Rubin (1939) reviewed 27 cases in which "lipiodol" was used for uterosalpingorrhaphy in which radiographs were taken from one month to one year afterwards. In 18 cases residual "lipiodol" was observed and in one further case an oil granuloma was subsequently removed at operation.

\section{PATHOLOGY}

Jacob and Fauré-Fremiet (1917) described the histological features of subcutaneous paraffnomata. By recognizing the similarity between these lesions and those seen in the lung, Pinkerton (1927) was the first to describe a "paraffinoma of the lung." The case was that of a boy aged 6 who had been given medicated liquid paraffin nose drops over a period of several months. At post-mortem examination, several firm, discrete nodules were found in the lung. Macroscopically these were considered to be neoplastic in origin, but section " showed the lung tissue to be virtually replaced by a loose connective tissue framework interspersed by numerous small lipoid droplets, large mononuclear cells, lymphocytes, and occasional eosinophils and neutrophils." In this case there were deposits of liquid paraffin in the bronchial lymph glands and the spleen. In several other cases he emphasized the presence of liquid paraffin in the peribronchial lymphatics and in one case he noted lymphoid follicles developing along the course of the oilcontaining lymphatics. Ikeda (1937) discussed 18 cases of the "adult type" recorded in the literature. These cases were due to the instillation of liquid paraffin, mostly intra-nasally, but a few cases fol $\stackrel{\overrightarrow{\vec{S}}}{\vec{s}}$ lowed oral administration. He stated that

"Liquid paraffin acts purely as a foreign body which is initially removed mainly by expectoration and partly by wandering phagocytes. The small amount of residual lipoid leads to a low-grade inflammation of the foreign body type. The active agents for which the liquid paraffin is a vehicle (e.g., menthol,,$\vec{P}$ thymol, and ephedrine) may set up an acute chemicaP reaction which, however, is of short duration. The pathological nature of the adult type of lipoid pneu. monia therefore is essentially that of a paraffinomas of the lung. Its various stages of development extend from an early non-suppurative proliferative inter:stitial pneumonitis to a chronic granulomatous foreign $P$ body reaction with widespread fibrosis and tume? faction of the involved area."

He described the three cardinal features as (1) a diffusely spreading fibroblastic proliferation which? obliterates the usual alveolar framework; (2) the widespread infiltration by plasma cells and lymphos cytes; (3) a few large, foamy macrophages within the stroma and irregular masses within the distorted alveoli. In the more fibrous areas alveoli are represented by distended spaces surrounded by $\mathrm{a}$ thick, densely fibrous collagenous connective tissue framework. These spaces are filled with oil which 5 tends to become adherent to the inner lining and often forms a large crescent giant cell. Numerous foreign-body giant cells are present and there are areas of pseudo-tubercle formation. Lymphoif nodules form along the course of the draining lymphatic presumably due to the rupture of these over-distended vessels.

Vascular changes in the lung containing liquide paraffin granulomata were first described b\% Hastings (1950), who stated that there was pros liferation of the elastic tissue in the walls of the blood vessels. Young, Applebaum, and Wasserê? man (1939) discussed a case in which there was a liquid paraffin granuloma of the lung with necros tizing changes in the kidneys, adrenals, and ovaries This case is remarkably similar to those publisheq. by Fienberg (1953) under the title of "Necrotising granulomatosis and angiitis of the lungs with massive splenic necrosis and focal thrombotic granulomatous glomerulo-nephritis."

\section{CASE Histories}

CASE 1.-A. V. C. was a man aged 50 who was asymptomatic until July 10,1952 , when he noticed hoarse ness, a dry cough, and, a week later, pleuritic pain i the left anterior chest. While under treatment wits injections and inhalations of penicillin, he developed $\frac{\pi}{\oplus}$ constant pain in the left shoulder and on two occasions had profuse night sweats. After a month his symptom abated and he returned to work. Within a week the 


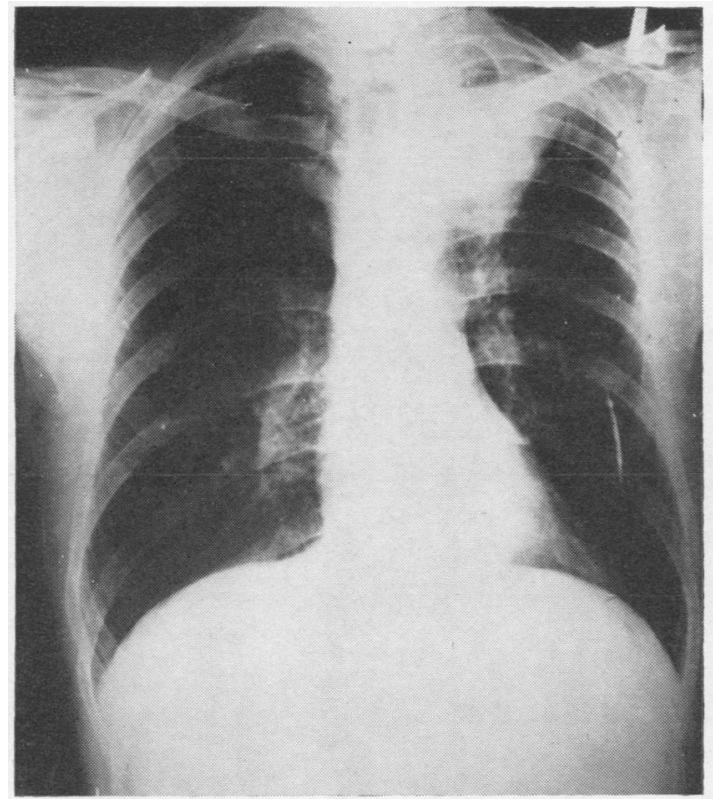

Fig. 1.-Radiograph of August 14, 1952, showing a dense left apical shadow with a suggestion of tissue breakdown and elevation of the hilum.

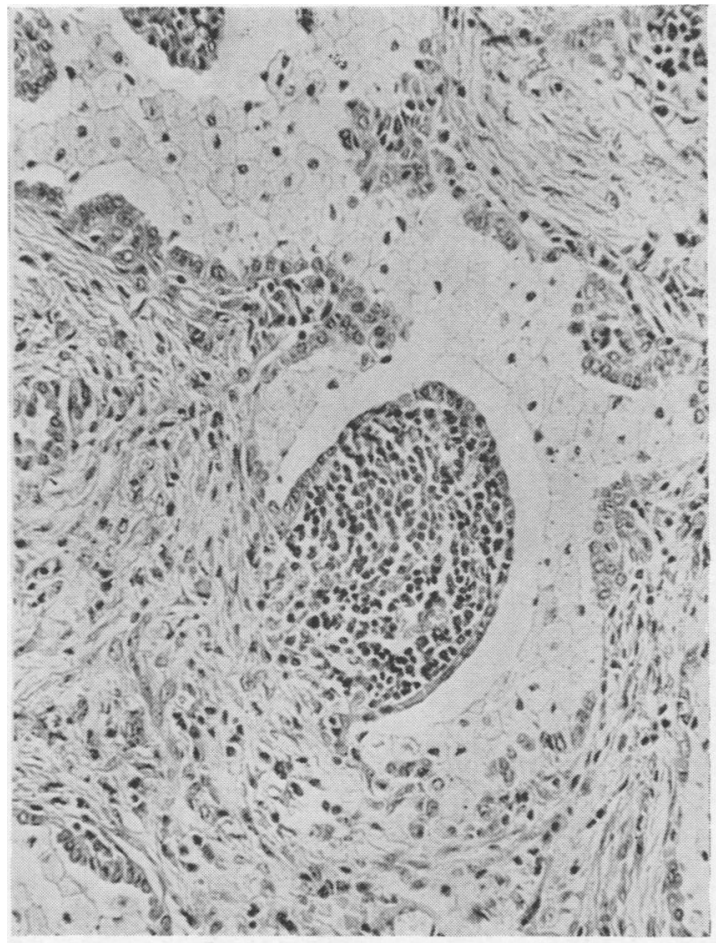

FIG. 3.-Photomicrograph showing accumulation of alveolar epithelium, lymphocytes, plasma cells and occasional multinuclear giant cells in one corner of the alveolus. Note cuboidal appearance of alveolar epithelium, $\times 140$

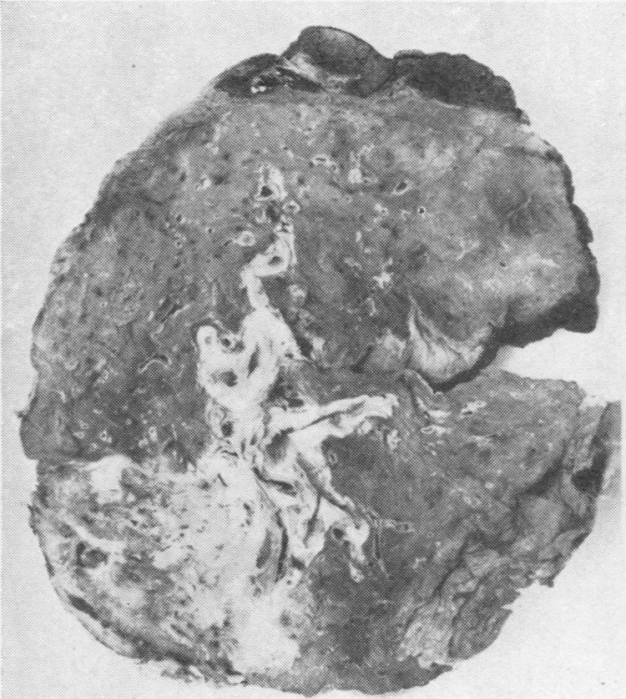

Fig. 2.-Specimen from Case 1 showing liquid paraffin granuloma.

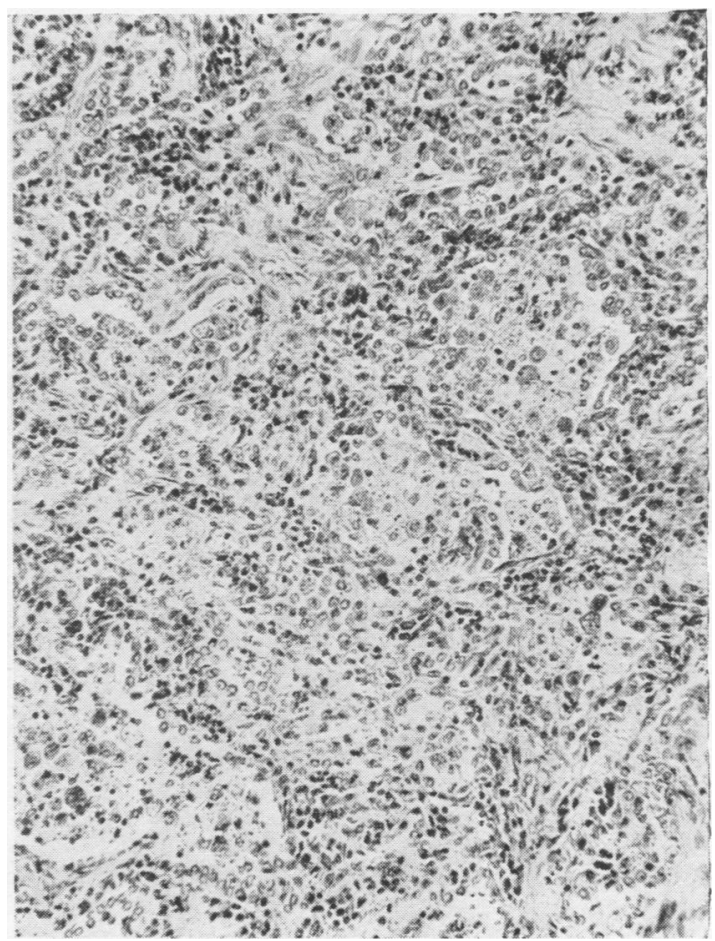

FIG. 4.-Section of the tumour showing foamy alveolar phagocytes containing liquid paraffin, $\times 120$ 


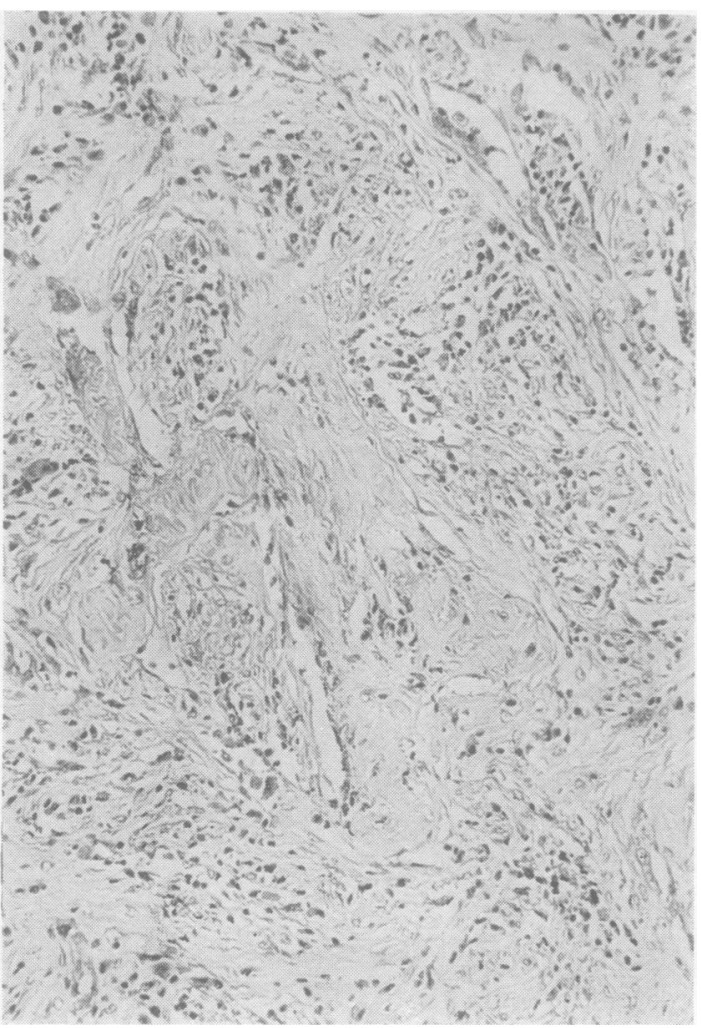

Fig. 5.-A fibrosed area in which a pedunculated mass of fibrous tissue projects into the alveolus, $\times 120$. .

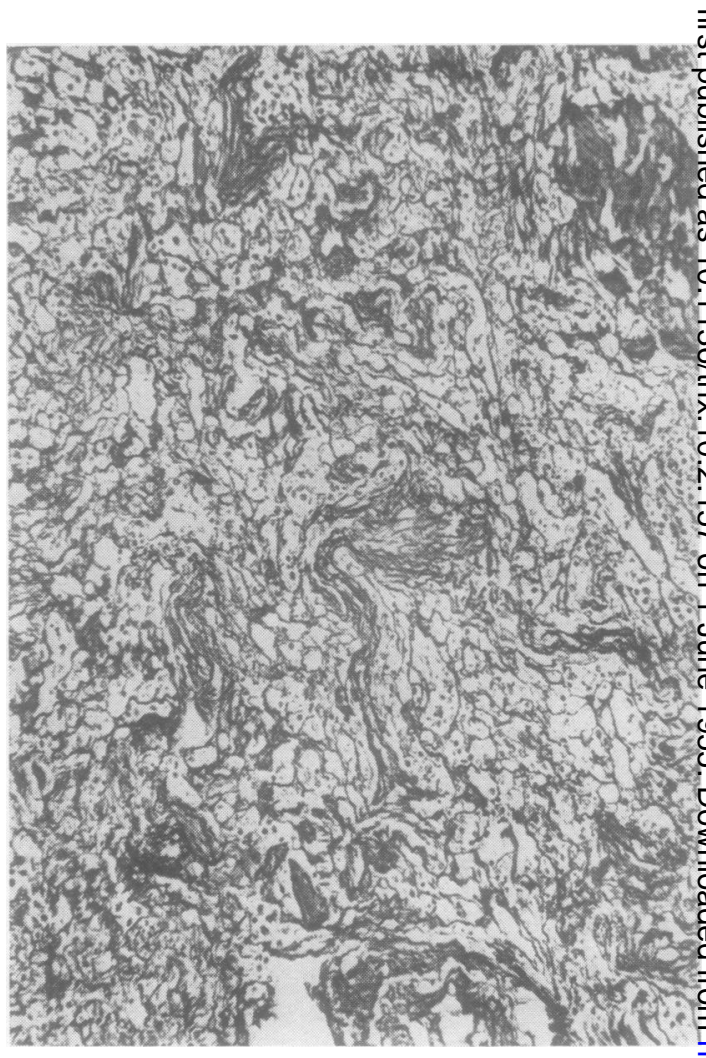

FIG. 6.-A general increase in reticulin in the necrotic area,

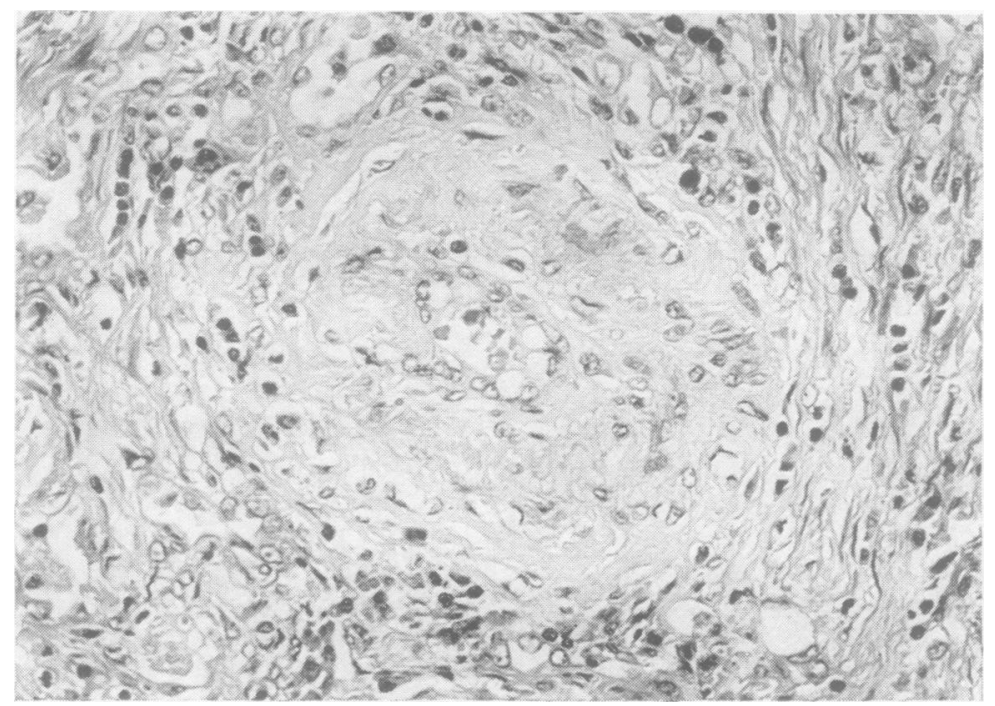




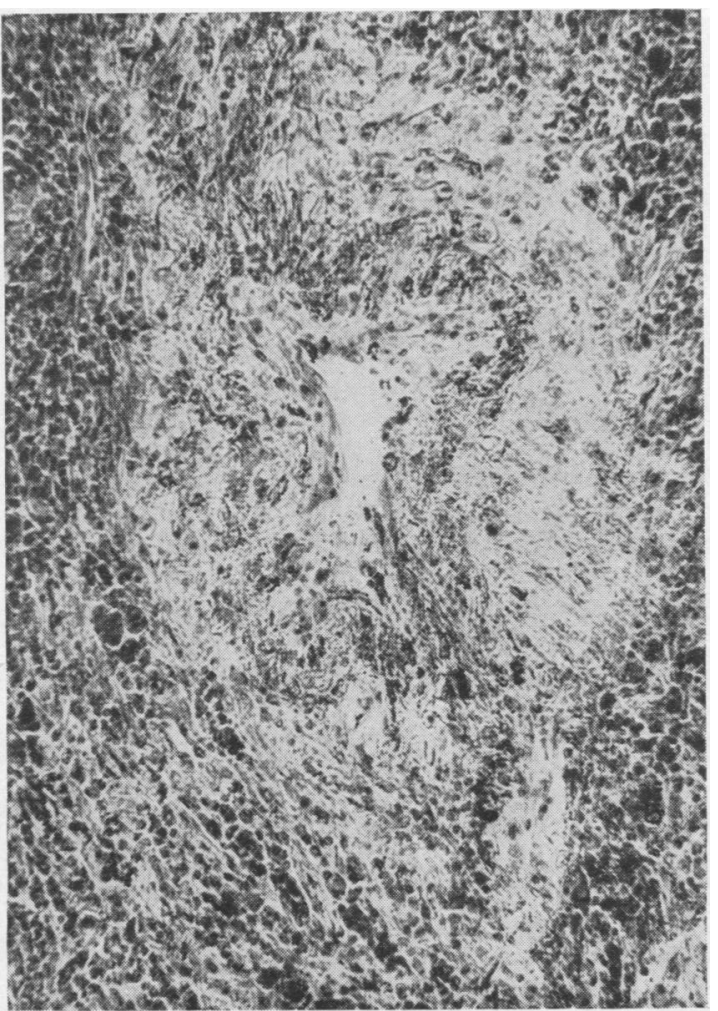

FIG. 8.-Sudan IV stain showing the lipoid in the lacunae in the wall of an arteriole, $\times 145$.

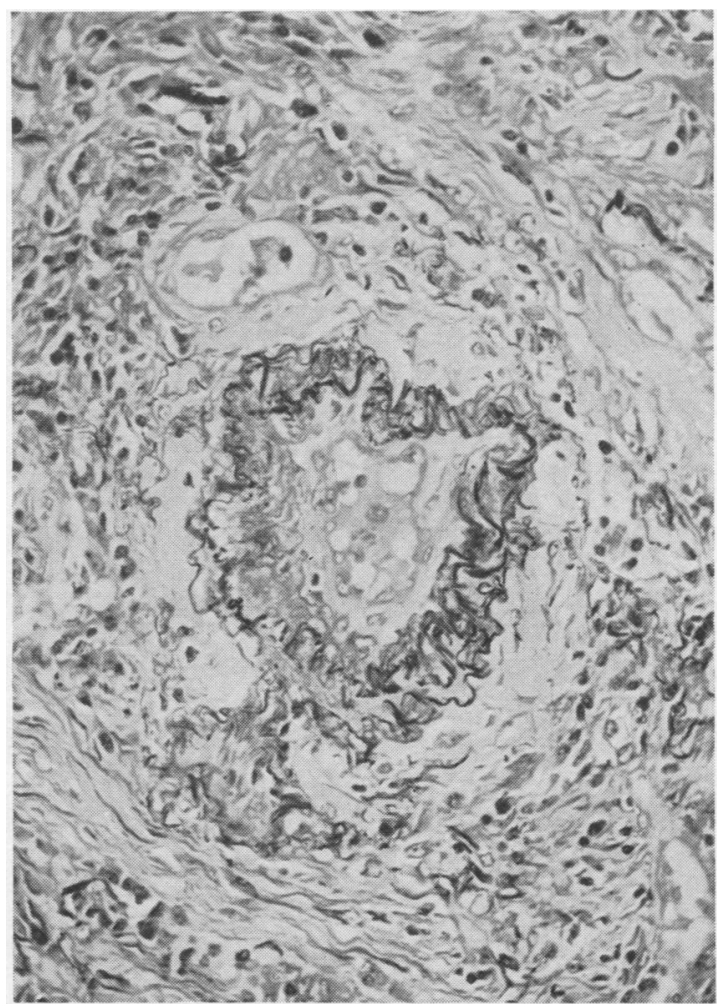

FIG. 9.-The fragmentation of the elastic laminae in the wall of the same vessel as shown in Fig. 6 is well demonstrated, $\times 230$.

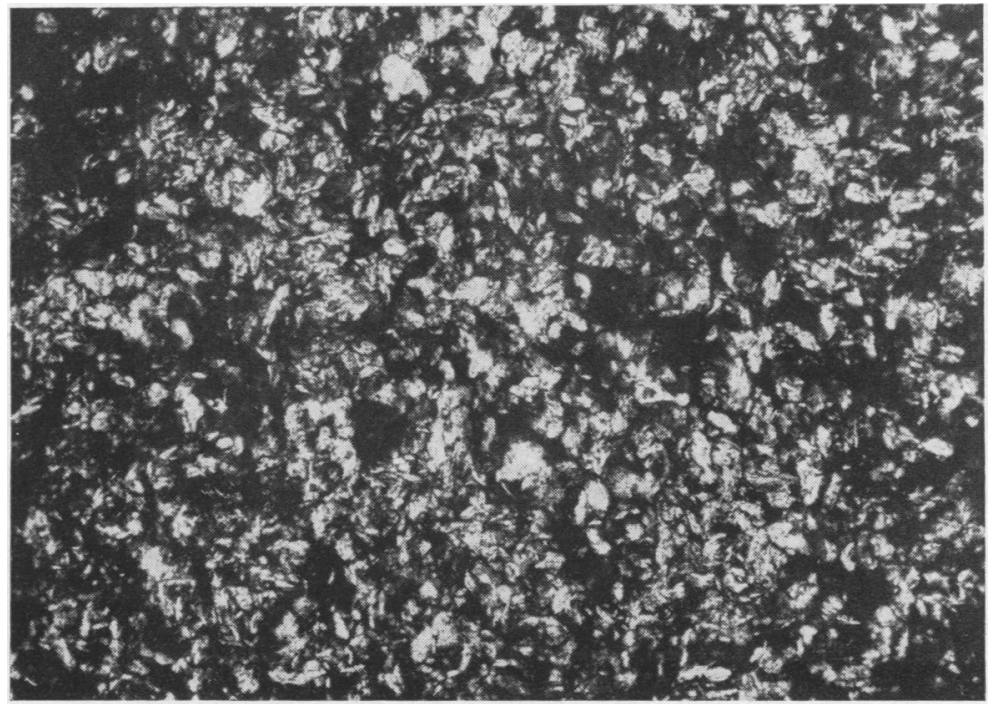

FIG. 10.-The needle-shaped crystals in the alveolar phagocytes in the granuloma, $\times 145$. 
cough recurred and became productive of offensive, creamish-brown sputum which was occasionally bloodstained. The pain also became more severe and was worse on lying down, so that he had to spend some nights sitting in a chair to obtain relief. On August 14 his chest was radiographed. The radiograph showed a dense left apical opacity extending to the sixth rib posteriorly, slight mediastinal displacement to the left and elevation, but no increase, in the left hilar shadows (Fig. 1). Two days later he was admitted to the medical wards of the Johannesburg General Hospital under the care of Professor Elliott. His previous history revealed that for many years he had suffered from sinusitis for which he had been treated intermittently with nose drops. It could not be ascertained subsequently whether these drops were oily. Apart from the fact that he had lost a little weight and had smoked 30 to 40 cigarettes daily for many years his history contributed nothing. On admission his pulse was 108 and his respirations were 28 per minute. His temperature was $100.6^{\circ} \mathrm{F}$.

Examination revealed a flushed individual with no abnormal physical signs apart from diminished movement and air entry with increased vocal resonance at the left apex. A blood examination showed no anaemia but a leucocytosis of 12,000 per c.mm. with a normal differential count. Pending further investigation penicillin, 500,000 units, was given twice daily and the initial fever ranging between $99^{\circ}$ and $103^{\circ} \mathrm{F}$. gradually dropped to normal by lysis at the end of the fifth week. On August 21 tomography demonstrated the lesion in all films from 6 to $13 \mathrm{~cm}$. in depth. Marked peribronchial thickening of the apical segmental bronchus was shown on the $12 \mathrm{~cm}$. cut and the $8 \mathrm{~cm}$. film showed similar involvement of the subapical bronchus.

On August 28 bronchoscopy showed no abnormality apart from broadening of the left upper lobe carina: suitably fixed bronchial slides and sputa did not reveal malignant cells. A further radiograph on September 16 showed the left apical lesion to be smaller, but tomography confirmed the previous findings and failed to demonstrate hilar glandular enlargement. A diagnosis of bronchogenic carcinoma was therefore made and left thoracotomy was performed on September 18. The lung was firmly adherent over the upper lobe, especially over three fairly well circumscribed areas where it had to be separated extrapleurally. The lung underlying these three areas was firmer than elsewhere. From the origin of the left upper lobe bronchus dense cords of peribronchial tissue could be felt radiating out to the three above-mentioned areas. A left pneumonectomy was performed and the paucity of hilar glands, mainly sub-aortic and the size of millet seeds, noted. Recovery from operation was uneventful.

Pathological Examination.-Macroscopically the left upper lobe showed a yellowish white tumour mass mainly in the subapical segment with extension into the apical segment. The pleura over the subapical segment was thickened and there was a small cavity $1 \mathrm{~cm}$. below the thickened pleura. The cavity had a fairly smooth wall and contained yellowish white inspissated material. These macroscopic appearances were very suggestive of a tuberculous cavity with infiltration by tuberculous granulation tissue around the cavity (Fig. 2).

Sections taken from the subapical segment showed a generalized obliteration of the normal lung tissue by loosely woven collagen fibres and fibroblasts, in which there were foci of lymphocytes and plasma cell infiltras tion, with occasional multinucleate giant cells. In this $\overrightarrow{0}$ fibrous tissue there were numerous irregular spaces,which on frozen section could be shown to contain oil. In the regions where the alveoli were still distinguishable they were grossly distorted and were either lined by ax cuboidal epithelium and contained foamy alveolarphagocytes in which sudanophilic material could be demonstrated (Fig. 3), lymphocytes, plasma cells, and multinucleate cells, or the epithelium was desquamated and the fibrous-walled alveoli were packed with foamy alveolar phagocytes (Fig. 4). In the more densely fibrosed areas groups of lymphocytes, plasma cells, and giant cells were surrounded by fibrous tissue which 5 separated them from the alveolar lumina resulting in $\mathrm{aD}$ pedunculated mass of fibrous tissue projecting into the alveolus (Fig. 5). In one region there was dense fibrous tissue with hyalinization of many of the collagen fibres; surrounding a necrotic focus in which there was a dense reticular network (Fig. 6). The most striking feature of these sections was the generalized endarteritis, whiclo was most marked in the arterioles. In some vessel the lumina were obliterated. This endarteritis was mos marked in the vessels surrounding the necrotic area Oil globules were observed in the lumina of some arterioles and small lacunae containing sudanophilie material were seen in their walls (Figs. 7 and 8). occasional obliterated vessels there was evidence of. recanalization.

The elastic tissue in the vessel walls appeared $t \vec{\Phi}$ have undergone a series of degenerative changes. In those arterioles in which there was early endarteritio change, the elastic laminae were contorted, with some fragmentation of the intervening elastic fibrils. The vessels in the walls of which the oil lacunae occurres showed fragmentation of the elastic laminae at the sit of the vacuoles (Fig. 9). In the fibrosed vessels the elastic tissue had completely disappeared or remainef as small fragments. Under a polarizing microscope numerous needle-shaped negatively birefringent crystalso were seen in the oil-containing alveolar phagocytes, in the vacuoles between the collagen fibres, and in the lacunae in the arteriolar walls (Fig. 10). These crystalls had a melting point of between 41 and $43^{\circ} \mathrm{C}$. IE addition the globules of oil in the lumina of the arterioles gave a "Maltese cross" effect on polarization (Fig. 11) On differential lipoid staining all the oil in this specimef stained rose-red with Sudan IV (Fig. 12), deep blue with Nile blue sulphate, did not reduce osmic acid, and no "lipiodol" was detected in the tissue using the techniquo described by Felton (1953). These histological an $\Phi$ histochemical features were consistent with those of liquid paraffin granuloma of the lung.

CASE 2.-C. C., a man aged 23, stated that in January 1952, he had 10 teeth extracted under general anaesthesi8 


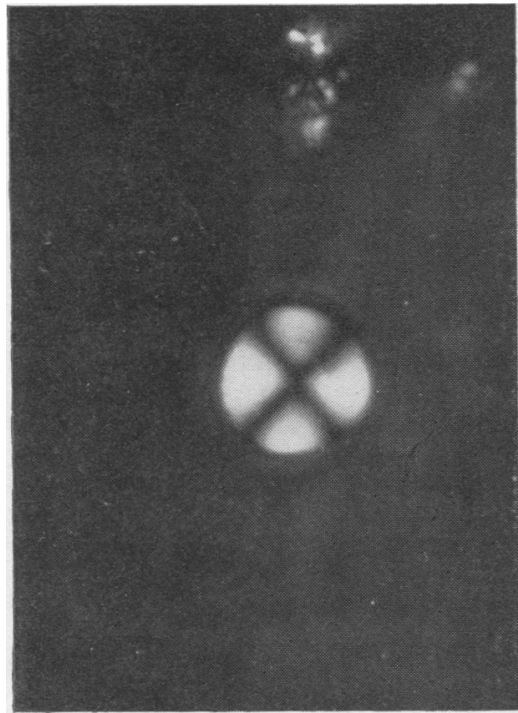

FIG. 11.-The spherite cross in one of the oil globules in Fig. 6. Some of the crystals in the walls of vessets are also demonstrated (polarized light, $\times 2,400$ ).

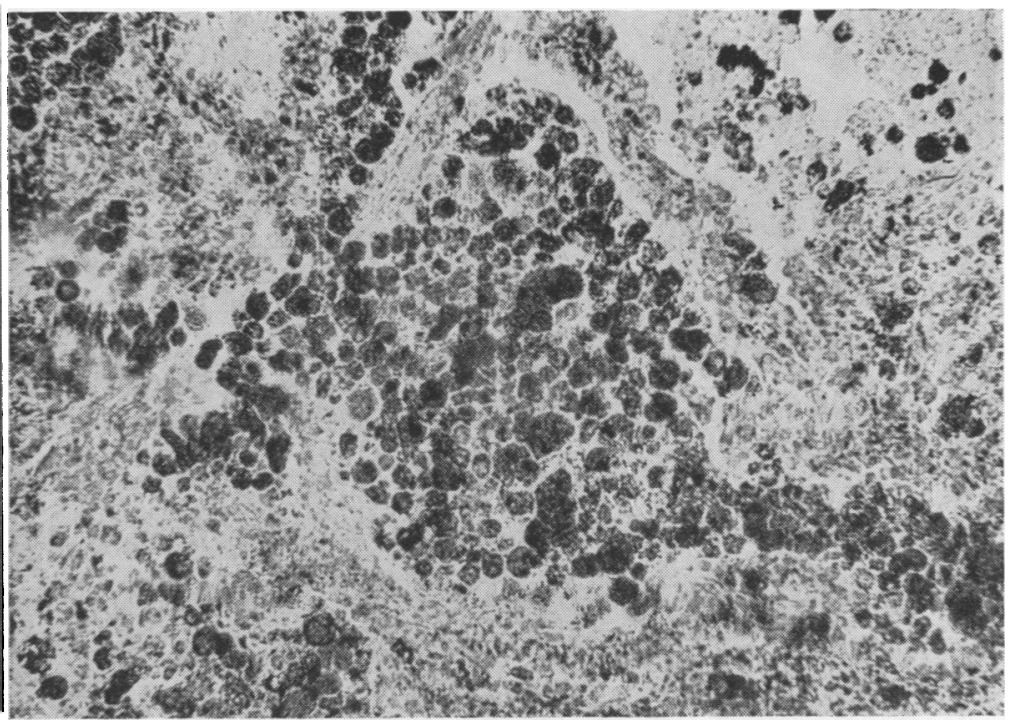

FIG. 12.-Sudan IV stain showing the oil-laden phagocytes, $\times 120$. and remained well despite the fact that a routine chest radiograph in February showed a lesion in the right lung. Subsequently he noticed some exertional dyspnoea which persisted till the onset of a severe pain in the right chest and fever in November. With this he developed a cough productive of thick white sputum and went to bed. After a few days he was given a sulphonamide and remained at home for three weeks. When he returned to work he felt tired and weak and developed an extremely severe pleuritic pain in the right chest anteriorly. This pain was worse on lying flat and on the right side, and because of it he was admitted on November 24 to the General Hospital under Dr. Sluis-Cremer.

Of note was a previous history of malaria and dysentery and the fact that for some months in 1949 he had used nose drops and a throat spray for hay fever. He had smoked 50 cigarettes and had drunk three-quarters of a bottle of brandy daily for the preceding 18 months. He had also come into contact with a brother who had pulmonary tuberculosis.

Examination revealed a well-developed patient with breathlessness and grunting respiration. He was not cyanosed nor was there any fever, but his pulse was 108 per minute. The only other abnormal clinical findings were a few crepitations and impaired air entry in the right axilla.

On the day of admission a chest radiograph showed emphysema at the right apex with a dense area of pneumonitis at the right mid-zone (Figs. 13 and 14). A tentative diagnosis of unresolved pneumonia was made and he was given 250,000 units of penicillin every six hours and symptomatic treatment. With this the mid-zone lesion regressed radiologically. Sputa were consistently negative both for tubercle and malignant cells. Bronchoscopy on January 6,1953 , revealed no abnormality and smears were taken from the right upper lobe and were negative for acid-fast bacilli and malignant cells.

On January 14 screening by Dr. H. Jackson demonstrated an obstructive emphysema of the right upper lobe. This was confirmed the following day by a bronchogram which showed the apical segment of the right upper lobe to be markedly emphysematous. The remaining segments were atelectatic and depressed. The rest of the bronchial tree was normal.

On February 24 right thoracotomy was performed. The apex of the right upper lobe was very distended and emphysematous and could not readily be deflated. The anterior segment was atelectatic. The axillary sub-segments of the right upper lobe were densely adherent to the chest wall. The underlying lung was firm and felt as though it contained a lung abscess. A prominent feature, however, was the peribronchial thickening extending to the origin of the right upper lobe bronchus and this suggested the possibility of an oil granuloma. Hilar glands were not noticeably enlarged. Right upper lobectomy was performed. Convalescence was uneventful with good re-expansion of the residual lobes.

Pathological Examination.-Macroscopically this right upper lobe showed an intact pleura and a partial fissure between the posterior and apical segments. The pleura of the posterior segment showed a yellowish discoloration. The apical segment was markedly emphysematous. The upper lobe bronchus was patent, and the posterior segmental bronchus was occluded by firm yellow tissue. On section the lung showed a diffuse, firm, yellow tumour mass in the posterior segment, extending to both the anterior and the apical segments.

The histological features were essentially similar to those described in the previous case, but were less 


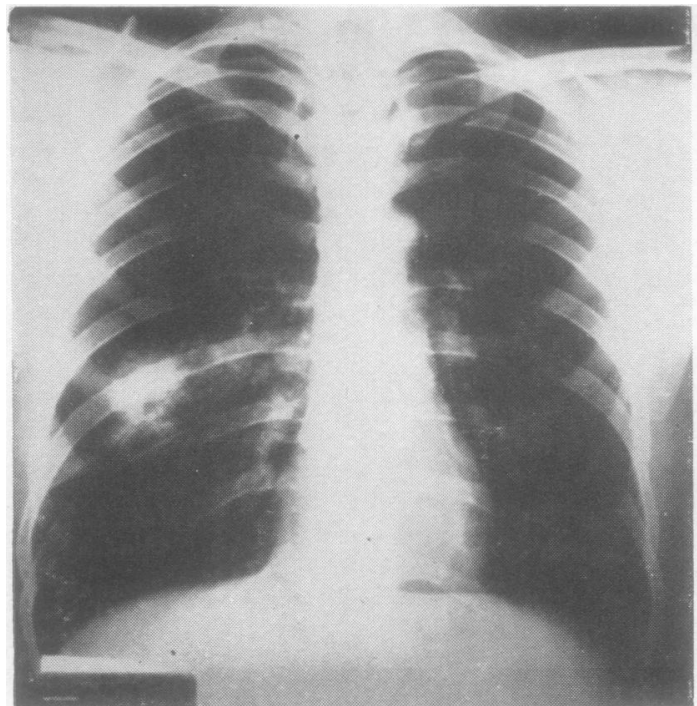

FIG. 13.-Radiograph of Case 2 on November 24, 1952, showing a shadow in the right lung field at the level of the right eighth rib posteriorly with gross emphysema of the right upper lobe.

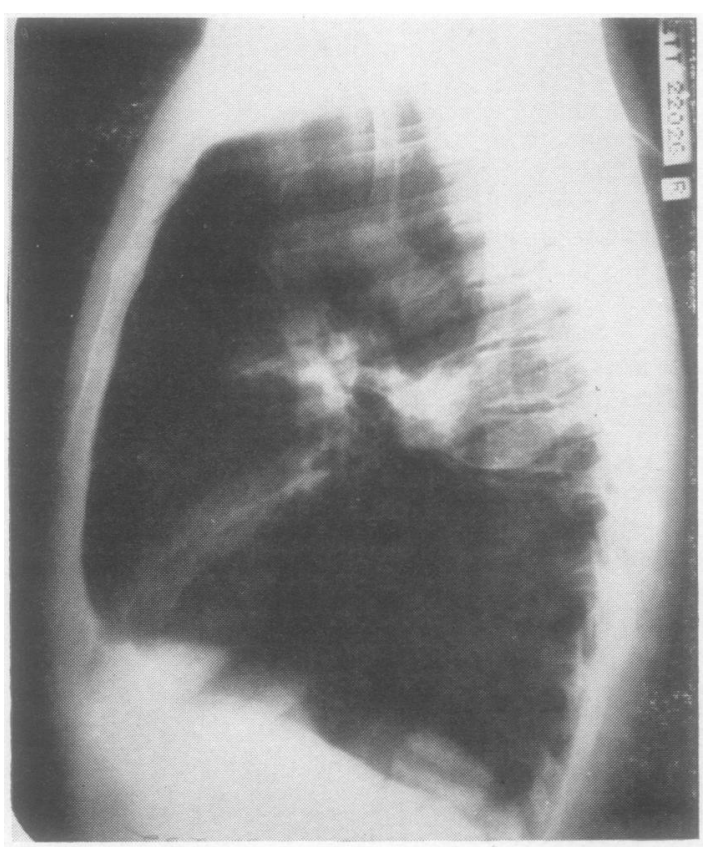

FIG. 14.-Lateral view of November 24 showing the lesion in the postero-lateral segment of the right upper lobe.

marked. Other prominent features of this case were the changes in the bronchioles and peribronchiolar regions.

This case was initially reported as a liquid parafiin granuloma in a lung in which there was a "follicular bronchiectasis."
Subsequent review of the sections showed that almost章 identical elastic tissue degeneration was taking place ino the bronchi and bronchioles as was occurring in theo blood vessels. This resulted in distorted irregular $\overline{\bar{s}}$. bronchi and bronchioles which had a bronchiectatic $\widetilde{D}$ appearance and contained acute inflammatory exudates. In addition, along the course of the distended peri-s bronchiolar lymphatics, which contained foamy alveolar ${ }_{\overrightarrow{0}}$ phagocytes and free globules of oil, numerous aggre:gations of lymphocytes occurred around globules of oil $\vec{\omega}$ Sections from the peripheral region of this specimen? showed the histological features of chronic emphysema $\overrightarrow{\vec{x}}$ In the hilar area and in the regions distal to the granu= loma, alveolar phagocytes containing iodized vegetable oil were seen and the ciliated columnar epithelial cells. lining the bronchi and bronchioles were distended and contained small globules of iodized vegetable oil.

The tumour itself contained only mineral oil andP there was no evidence of iodized vegetable oil in the alveolar phagocytes within the tumour area, although bronchial epithelium and alveolar phagocytes lying freed in the adjacent portions of the lobe contained iodized vegetable oil.

CASE 3.-C. R., a man aged 22, was admitted to the Thoracic Surgical Unit on September 17, 1951, fop investigation and treatment. In 1947 he had a ribs resection for a left-sided "empyema" which draineচ for three months. Following that he experienced frequent attacks of fever and of malaise. These occurre $\mathbb{B}$ almost monthly at first, but gradually the intervals had increased and he had attacks three or four times year. Before admission he had a slight constant ache below the left nipple and through to the back. He had noticed dyspnoea when playing football, but at no time did he suffer from any cough. A radiograph (Fig. 15) on admission showed a large spherical homogeneous

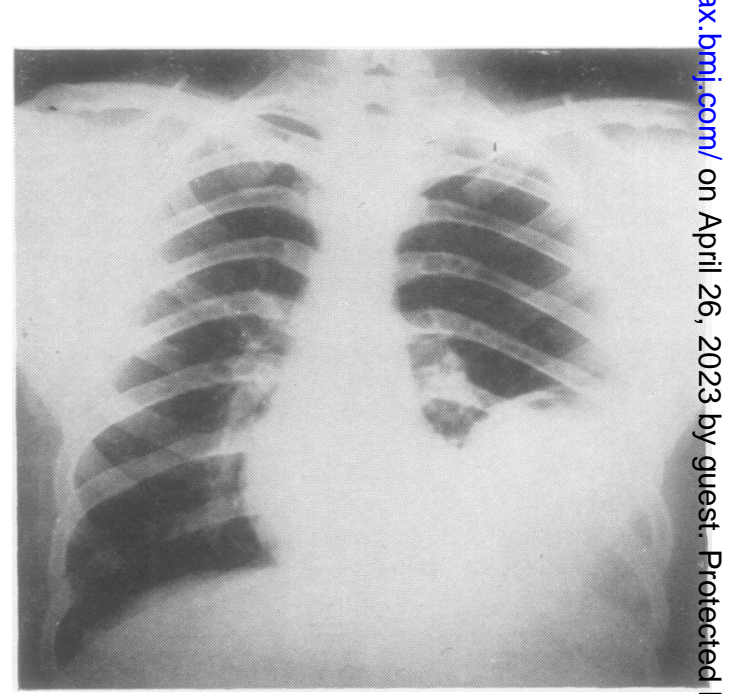

FIG. 15.-Radiograph of Case 3 on September 17, 1951, showing spherical shadow at the left base extending up to the lower border of the sixth rib with a small fluid level. 


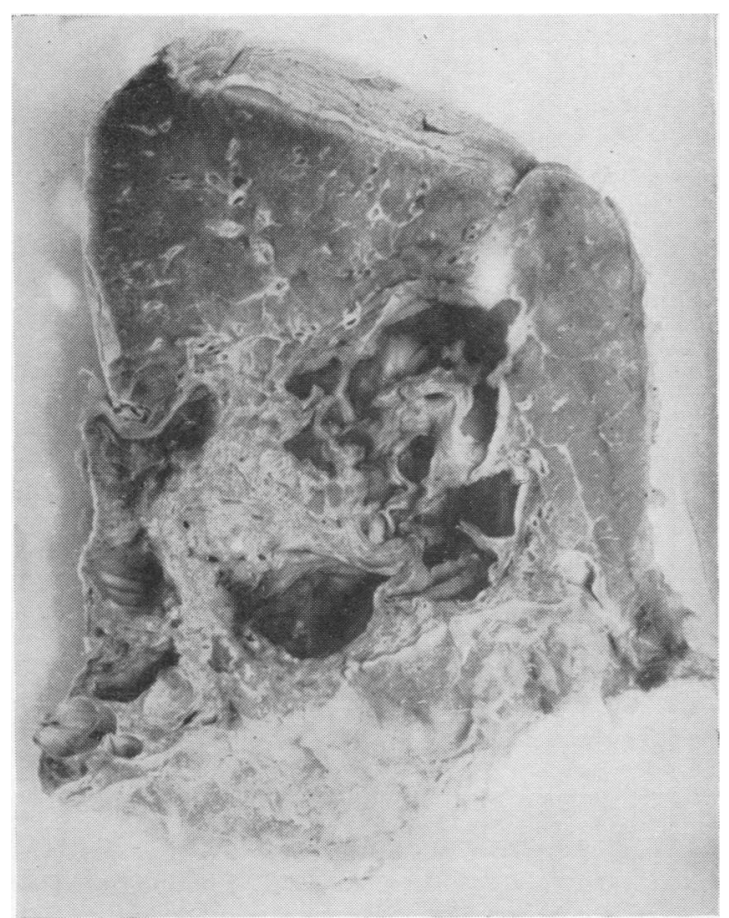

FIG. 16.-Specimen showing tumour situated in the middle of lung cysts.

opacity in the left posterior costophrenic sulcus but extending well up into the chest. At the summit of this level was a small fluid level. On September 19 $400 \mathrm{ml}$. of thick, green mucus was aspirated. A diagnosis of a congenital sequestrated cyst was made.

On September 26 a left thoracotomy was performed. The cyst, inseparable from the left lower lobe, was only adherent to the site of the previous rib resection. It was inadvertently opened and $600 \mathrm{ml}$. of mucoid material was aspirated. A left lower lobectomy was performed with division of an aberrant artery arising from the aorta just above the diaphragm. Convalescence was marred by atelectasis of the left upper lobe and persistent effusion necessitating decortication, after which he remained well and asymptomatic.

Pathological Examination.-In the left lower lobe there was a large multiloculated cyst surrounding a diffuse golden-yellow tumour (Fig. 16). The microscopical features of this tumour were similar to those described in the first case with the oil showing the histochemical features of liquid paraffin. Sections from the cyst showed it to be lined by a pseudo-stratified columnar respiratory epithelium. In the lumen blood clot and amorphous eosinophilic material containing numerous cholesterol crystals were demonstrated.

CASE 4.-H. C. B., a male clerk aged 46, was referred for opinion on October 8,1953 . He stated that he had been well until September, 1951, when he developed fever, pain, and cough with some blood streaking diagnosed as pleurisy. From that time he had been

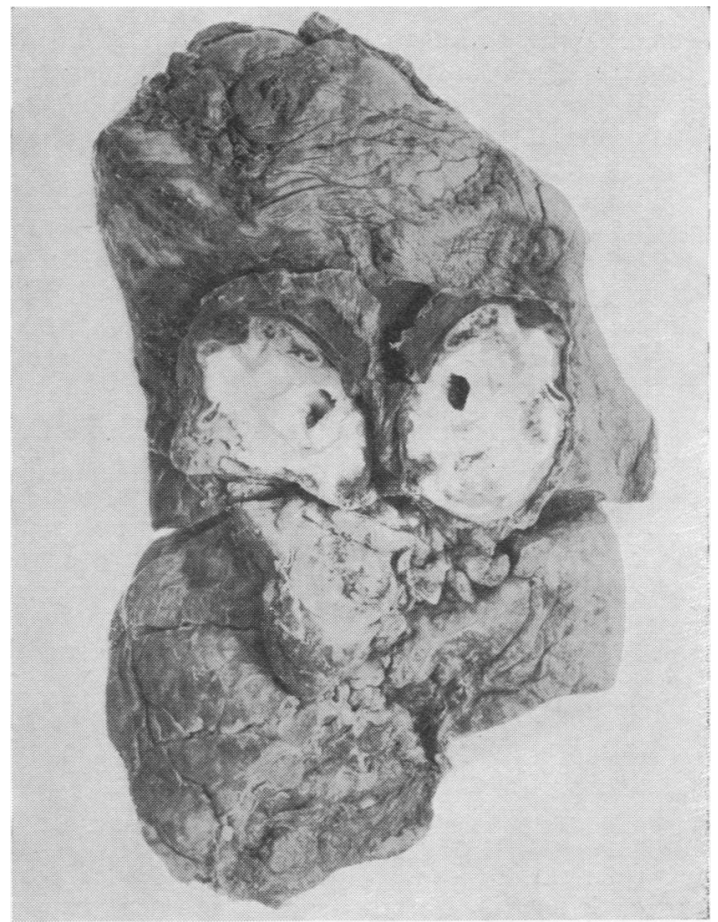

Fig. 17.-Section from a liquid paraffin granuloma showing a pseudotubercular appearance, $\times 210$.

prone to chest colds, and had two further attacks of pleurisy, and had been subject to repeated small haemoptyses but was otherwise well. He had smoked 40 to 50 cigarettes daily for about 20 years, and for many years had used oily nose drops nightly.

Clinical examination showed dullness, absent air entry, and resonance below the right clavicle. Radiological examination showed a dense opacity (Fig. 17) in the antero-lateral segment of the right upper lobe with an extension to the upper pole of the right hilum. A tentative diagnosis of bronchogenic carcinoma was made. Bronchoscopy revealed no abnormality, but a dionosil bronchogram showed a block of the apical and anterolateral segmental bronchi. Examination elsewhere showed no malignant cells in the bronchial smears.

In view of the two-year history, the normal upper lobe bronchus on bronchoscopy, and negative smears the alternative diagnosis of an oil granuloma was suggested. Right thoracotomy on October 15 showed dense adherent apical and antero-lateral segments with enlarged rubbery hilar and paratracheal glands. The origin of the right upper lobe bronchus was normal, but distally there was complete obstruction from a hard mass. Frozen section on a paratracheal lymph gland was reported upon as being consistent with the histological features of a lymph gland associated with oil granuloma. A right upper lobectomy was therefore performed. The lobe was immediately sectioned, fat could be squeezed out of its substance, and frozen sections confirmed the diagnosis of an oil granuloma. 
Pathological Examination.-Macroscopic examination showed a large white necrotic hilar tumour, involvement of the lymph nodes, and obstruction of the anterolateral and apical segmental bronchi. These segments were atelectatic, yellowish, and oily to the touch.

Histological examination showed a large-celled carcinoma arising from the upper lobe bronchus. Beyond this the obstructed segments showed the features of an oil granuloma similar to those described above. Paraffin sections of the lymph node previously submitted for frozen section showed infiltration with metastatic carcinoma as well as the oil granuloma.

CASE 5.-Miss L. E. aged 57 was first seen in consultation on February 21, 1954. She stated that she had always been well apart from a mild chronic sinusitis for which she had used a proprietary oily nasal medicament. In October, 1953, she developed a fever, myalgic pains, and a sore throat. From this she rapidly recovered, but then developed a cough productive of a little mucopurulent sputum which had persisted despite intensive antibiotic therapy. Sputa were negative for tubercle bacilli and radiological investigation showed a wellcircumscribed spherical opacity in the left upper lobe.

With this history she was admitted to the Thoracic Surgical Unit of the Florence Nightingale Nursing Home. Bronchoscopy revealed no abnormality, but bronchial smears showed occasional cells with hyperchromatic nuclei. No other site for a primary tumour could be established. A tentative diagnosis of bronchogenic carcinoma was made.

On March 3 a left thoracotomy was performed. A small mobile mass was felt and a node removed. This node, on frozen section, was reported upon as being infiltrated with carcinoma. Left upper lobectomy was, however, performed and from this she recovered uneventfully.

Pathological Examination.-Macroscopic examination of the lobe showed a well-circumscribed spherical whitish mass, $2 \mathrm{~cm}$. in diameter, in the antero-lateral segment of the left upper lobe. The appearances of this mass were compatible with a degenerating carcinoma (either primary or secondary), a tuberculoma, or an oil granuloma.

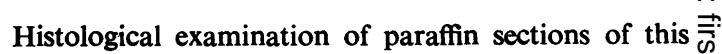
mass and of the glands submitted for frozen section showed the typical features of an oil granuloma.

The Biochemical IDENTIFICATION OF THE OIL Derived from Lung Granulomata

Biochemical analysis was undertaken on specimens from the first three cases which were of the $\vec{O}$ adult type of granuloma. As Graef (1939) has shown, the total amount of fat recovered from ${ }_{\circ}^{\omega}$ these granulomata is slightly more than that which $\overrightarrow{\vec{x}}$ is found in healthy lung tissue, i.e., $10 \%$ of the dry weight. Using the method described by Graef (1939) our results on the five cases presented in? this paper are:

\begin{tabular}{c|c|c|c|cc}
\hline Case & $\begin{array}{c}\text { Weight of } \\
\text { Wet } \\
\text { No. }\end{array}$ & $\begin{array}{c}\text { Freeze- } \\
\text { dried } \\
\text { Residue } \\
\text { (g.) }\end{array}$ & $\begin{array}{c}\text { Total } \\
\text { Fat (g.) }\end{array}$ & $\%$ & (g.) \\
\hline 1 & 5.5 & 1.047 & 0.155 & 15 \\
2 & 4.3 & 0.635 & 0.132 & 20 \\
3 & 5.0 & 0.854 & 0.141 & 16.6 & $心$ \\
\hline
\end{tabular}

Using a minor modification of the method described by Donnelly and Hecht (1952), we were able to extract a small amount of oily fluid from the granulomas. We are not satisfied that the $\stackrel{\perp}{\circ}$ substance extracted either by this method or by $\overrightarrow{\overrightarrow{0}}$ the method described by Jampolis, McDonald, and Clagett (1953) is liquid paraffin.

\section{HISTOCHEMISTRY}

The histochemistry of lipoids in the lung was initially investigated by Pinkerton (1928). Following this it was accepted that liquid paraffin could be distinguished from animal and vegetable oils by being stained salmon pink with Sudan IV and dark blue with Nile blue sulphate and did not reduce osmic acid.

TABLE I

REACTIONS OF “ LIPOIDS " IN VITRO

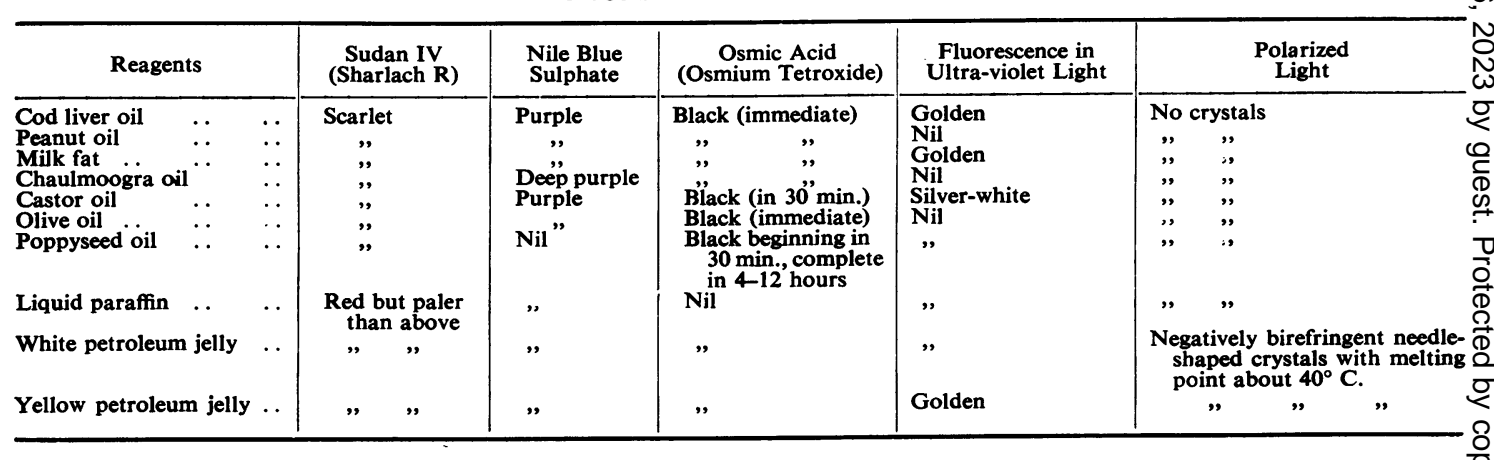


In in vitro experiments one of us (J. C. W.) obtained the results shown in Table I.

At first we accepted the above criteria, but on reviewing the literature on lipoid histochemistry (Pearse, 1953; Gomori, 1952; Cain, 1950; Thannhauser, 1950) it became apparent that these criteria were not acceptable, as the same reactions could be obtained with cholesterol, the other steroids, the phosphatides, and the cerebrosides. Another assumption which was found to be incorrect was that all negatively birefringent crystals were cholesterol. The crystals in this series of oil granulomata are negatively birefringent and have a melting point of $41-43^{\circ} \mathrm{C}$. A false clue to their origin was the discovery that in petroleum jelly there are needle-shaped birefringent crystals with a melting point of approximately $40^{\circ} \mathrm{C}$., but these crystals give a negative reaction to Schultz's modification of the Liebermann-Burchardt reaction (Gomori, 1952), whereas the crystals in the oil granulomata gave a positive reaction. Cholesterol and its esters have a melting point of above $140^{\circ} \mathrm{C}$. Cain (1950) states that as far as is known the Liebermann-Burchardt reaction is a specific test for cholesterol in animal tissues.

To confirm the origin of the crystals a study was made of the reaction of crystals in sections from the gall bladder in a case of hypercholesterolosis. In these sections two forms of negatively birefringent crystals were observed, viz., the true cholesterol crystals and small, needle-shaped crystals similar to those seen in the lung granulomas. Both these forms of crystals gave a positive Schultz reaction. The needle-shaped crystals melted at approximately $42^{\circ} \mathrm{C}$. and the large crystals showed no evidence of disintegration at a far higher temperature. As Cain (1950) states, "A particularly important characteristic of lipoids is their ability to dissolve in each other, sometimes to a considerable extent." In view of this it seemed probable that in the gall bladder we were dealing with a combination of cholesterol and a neutral fat.

As a result of this, the possibility of the lipoid in the granulomata consisting of a combination of liquid paraffin, cholesterol, and a "neutral fat" or " neutral fats" was considered. To demonstrate this a modification of Keilig's extraction method (Pearse, 1953) was used. It was found that liquid paraffin is insoluble in cold acetone but soluble in cold ether and cold chloroform.

Frozen sections were cut at $15 \mu$ and agitated in cold acetone for five minutes. Then as a control some of these sections were removed from the acetone, stained with Sudan IV and Sudan black " $B$," and unstained sections were mounted for examination with a polarizing microscope. Additional sections were prepared for the Schultz reaction. It was found that on Sudan staining the Sudanophilic material was present in exactly the same distribution as in the untreated sections but the Schultz reaction was now negative, the crystals had disappeared but the spherite crosses persisted. The remaining sections were then washed in distilled water and placed in cold ether for 10 minutes. These sections were then stained with Sudan IV and Sudan black "B" and examined under a polarizing microscope. Small deposits of Sudanophilic material were observed in alveolar phagocytes and in the interstitial tissue and the spherite crosses were still present.

From Keilig's conclusions (Pearse, 1953) it was assumed that the remaining small foci of lipoid were either cerebrosides, phospholipids, or sphingomyelins. In the one specimen of this series that was not in formalin Baker's acid haematin test (Baker, 1946) was negative for phospholipids. These crystals were present in unfixed sections of this specimen, suggesting that they are not the result of formalin fixation.

The obvious control of this experiment would be to extract the liquid paraffin from the ether and identify it chemically. This is being done, but we are informed by organic chemists that it will be extremely difficult because of the inert chemical nature of the substance and the fact that it consists of a series of hydrocarbons. The exact nature of the crystals is being investigated. The fact that they have been observed in several other types of granuloma, which have definite and proved aetiologies, suggests that they may play an important role in initiating the fibrous tissue reactions which is a sequel to many of the "foreign body" lesions.

\section{Clinical Diagnosis of Mineral Oil Granuloma}

As this is a relatively uncommon condition a pre-operative diagnosis will probably seldom be made, particularly as the clinical and radio'ogical features are so suggestive of a diagnosis of carcinoma, tuberculosis, or lung abscess. Most of the cases described have occurred in the posterior segments of the upper lobes and in the apices of the lower lobes, but these sites are also commonly involved in both tuberculosis and lung abscess. At operation the condition can be suspected by firm peribronchial cords radiating to the hilum, which is singularly free of enlarged glands.

Although the diagnosis can be made with certainty on histological examination, the findings bear no relation to the duration of any known or suspected aetiological factor. In Case 1, although 
the lesion showed marked fibrosis with areas of necrosis the history of symptoms was only nine weeks and during that time the patient used nose drops on rare occasions. It should be noted that Storrs, McDonald, and Good (1949) found an established granuloma 19 days after bronchography. In Case 2, despite nasal drops and a nasal atomizer having been used some years previously, examination of this tumour showed less fibrosis and endarteritis than did the first case. In Case 3 there is no previous history of the use of "lipiodol " or nasal oil drops, and no communication could be detected between the sequestrated cyst and the bronchus. Possibly, at the time that the " empyema" was drained in 1947 some petroleum oil product was used in the wound packs. Both Cases 4 and 5 had used oily nose drops regularly for years.

A history of instillation of oily nose drops would add weight to a tentative diagnosis of mineral oil granuloma. Examination of sputa from patients with suspected oil granulomata of the lung has not been helpful. Because of the fibrous nature of the lesions the possibility of liquid paraffin appearing in the sputum is remote. The mere finding of cells containing "lipiodol" in the sputum does not indicate an oil granuloma, as these cells can be seen in the sputum for varying periods in patients who have had a "lipiodol" bronchogram, and do not harbour a granuloma. In two of our patients who had bronchograms done pre-operatively, although the alveolar phagocytes in the adjacent portion of the lung contained "lipiodol," none was found in the granuloma.

\section{The Pathogenesis of Oil Granulomata in the LUNGS}

On the histopathological and histochemical evidence from the examination of these cases of oil granulomata and of cases of lipoid pneumonia in infants, and from a review of literature, the following hypothesis as to the pathogenesis of oil granuloma in the lungs is suggested. This can be divided into four consecutive stages (Fig. 18), but any or all of these processes may be present in a single lesion.

StAGE I.-This stage can be seen in infants who die of asphyxia following massive inhalation of milk. There is altered milk in the bronchi, bronchioles, and alveoli surrounded by scanty neutrophils, lymphocytes, and occasional giant cells.

STAGE II.-This is the stage of absorption and foreign body reaction. Numerous alveolar phagocytes appear in the alveoli and begin absorbing the fat globules and the oil in the perivascular and peribronchiolar lymphatics (Figs. 4 and 12). Once the oil is taken up by the alveolar phagocytes, the needle-shaped crystals are observed in these cells (Fig. 10). As this stage of foreign-body reaction continues, most of the oil is absorbed by the alveolar phagocytes, which now have a distended foamy cytoplasm. These, together with numerous lymphocytes, plasma cells, and occasional multinucleate giant cells, are present in the alveoli. The alveolar walls now appear thickened and the alveolar epithelium cuboidal. Some of these cells contain oil and needle-shaped crystals. In the alveolar walls there is an increase of reticulum with noticeable collagen fibres and occasional fibroblasts. The lymphatic tissue has become hyperplastic and lymph nodules with germinal centres are seen. Along the course of the lymphatics there are aggregations of lymphocytes around globules of oil and in some of these areas the aggregations are so compact that they resemble lymph nodules. In occasional arterioles and venules globules of oil can be identified. The last two observations were first made by Pinkerton and Moragues (1940). These globules have a spherite cross (Maltese cross) appearance in polarization (Fig. 11). In addition there is increased perivascular fibrous tissue and the internal and external elastic laminae of the arterioles are grossly contorted and their endothelial cells appear to be swollen. In the bronchi and bronchioles the epithelial cells swell and fibrous tissue and reticulum fibres in the muscularis increase. The elastic tissue is present and intact. The alveoli contain lymphocytes, plasma cells, occasional oil-containing alveolar phagocytes, and multinucleate giant cells.

STAGE III.-This is the stage of elastic tissue degeneration and endarteritis. The alveoli are distorted and many of them have collapsed. The lymphocytes and plasma cells have disappeared from the alveolar spaces, which now only contain compressed oil-containing phagocytes, occasional multinuclear giant cells, and desquamated alveolar epithelial cells. In the alveolar walls there is a marked increase in reticulum and the capillaries are completely replaced by collagen fibres and fibroblasts. In the areas where the alveoli are no longer discernible, the normal lung structure is obliterated by a loose weave of collagen fibres and fibroblasts, enmeshed in which are oil-containing phagocytes, globules of oil, multinucleate giant cells, and clumps of lymphocytes, plasma cells, and eosinophils. In addition there are occasional foci of multinucleated giant cells surrounded by 


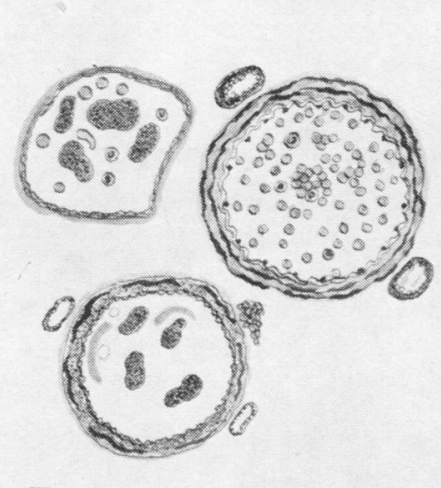

I
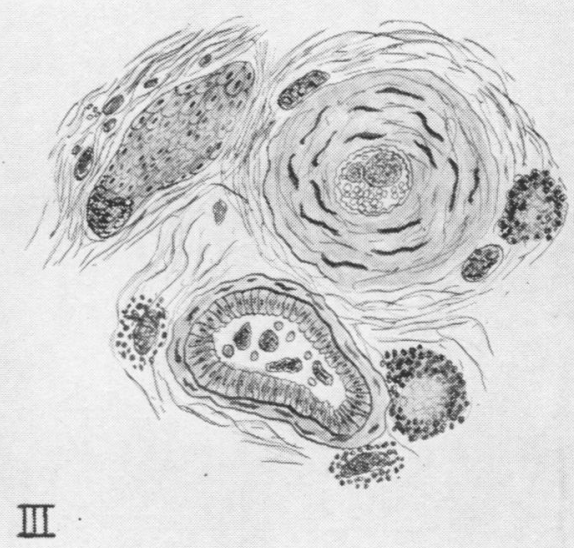

III
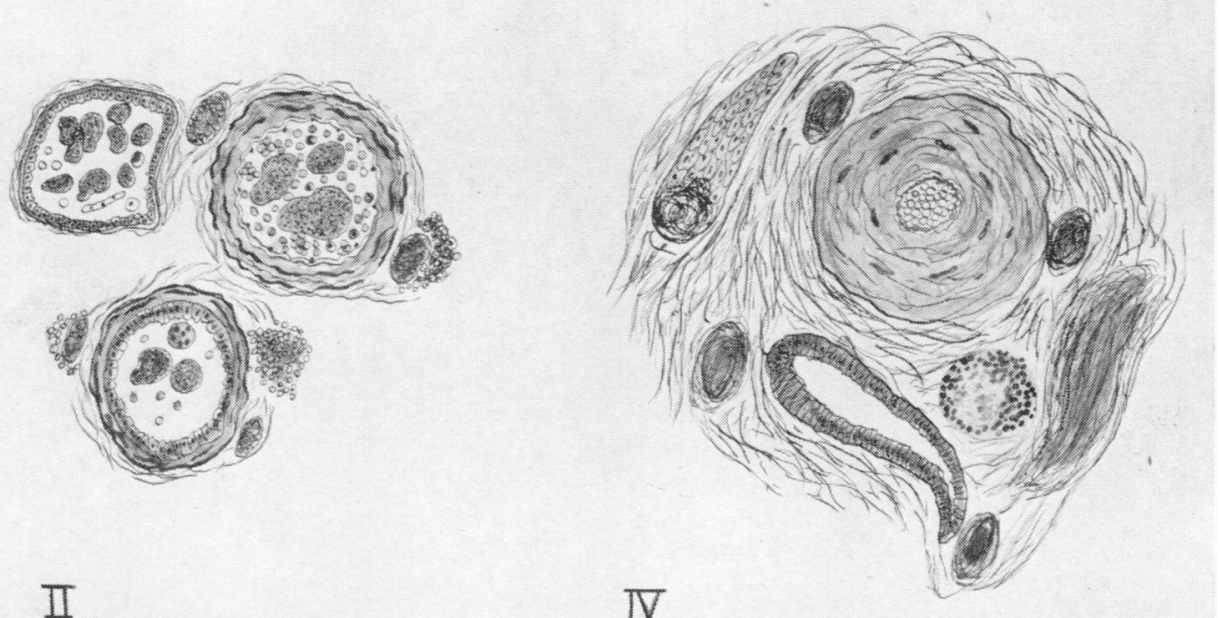

FIG. 18.-This diagram illustrates the four stages in the pathogenesis of these lesions.

palisading epithelioid cells. The appearance of these foci is similar to those of proliferating tuberculosis. The changes in the arterioles are most significant and striking. The fibrosis of the adventitia has greatly increased and the muscle in the media has been entirely replaced by fibrous tissue. In all three layers of the walls numerous small vacuoles are seen. On frozen section these vacuoles are seen to contain oil (Fig. 8) and the needleshaped negatively birefringent crystals. Wherever the elastic fibres and elastic laminae come into contact with these vacuoles, there is disruption of the elastic tissues giving the elastic fibres a markedly fragmented appearance (Fig. 9). The lumina of the blood vessels are greatly reduced (Fig. 7). In the walls of the bronchi and bronchioles a similar appearance to that of the arterioles is seen with a similar vacuolation, disruption of elastic fibres, and fibrous replacement of the muscularis. The lumina of the bronchi and bronchioles are dilated and irregular in outline, giving a bronchiectatic appearance. Surrounding the peribronchial lymphatics lymphoid tissue is markedly hyperplastic, and the aggregations of lymphocytes around the oil globules now appear as mature lymph nodules. These histological features are strikingly similar to those described by Whitwell (1952) as "follicular bronchiectasis."

STAGE IV.-This is the stage of increasing fibrosis. In it there is an increasing fibrosis with a progressive endarteritis. The elastic tissue in the arterioles, bronchi, and bronchioles is gradually replaced by a reticulum network (Fig. 6), and the previously dilated bronchi and bronchioles become collapsed and stenosed by the ever-increasing interstitial fibrosis. The final picture is one of completely 
occluded arterioles and flattened degenerating bronchi and bronchioles, surrounded by dense fibrous tissue in which there are areas of hyaline degeneration and necrosis. Between the collagen fibres occasional compressed globules of oil are seen (Fig. 5). In any one of these stages secondary infection may distort the histological features.

\section{CONCLUSIONS}

Oil granulomata of the lung are not rare and should be considered in the differential diagnosis of all chronic lung lesions where the more common diseases such as tuberculosis and carcinoma have been excluded. Such cases are preventable, and the widespread chronic use of oily nasal drops and vapours should not be allowed. Persons occupied in industry involving the use of oil sprays should be adequately protected.

In four of our five cases the granuloma was situated in the upper lobes, a site in keeping with an inhalation mechanism.

The clinical symptomatology and pathological lesions following inhalation are variable. Two of our cases presented as a mass indistinguishable from bronchogenic carcinoma, one was associated with a carcinoma, one presented with atelectasis and obstructive emphysema of an upper lobe, and the fifth was associated with a previously drained empyema.

\section{SUMmary}

Five cases of mineral oil granuloma of the lung are presented and the literature is reviewed.

It is suggested that the pathogenesis of mineral oil granulomata of the lung is due to the sclerosing effect of an endogenous fatty acid to lipoid.

The difficulties of pre-operative diagnosis are discussed
The dangers of using oils internally as a vehicle for medicaments or radio-opaque substances is stressed.

We would like to thank Frofessor Guy Elliott, Dr. Sluis Cremer, Dr. Miedalie, and Dr. Frack for referring these cases. Case No. 4 was referred by the late Dr. J. Baynash. We should also like to thank Dr. F. A. Brandt for the photography, Mr. D. Treurnich for preparing the sections, Mr. H. D. Barnes for the biochemistry, Mr. J. de Bruyn for the diagrams, and Dr. C. Komins, of the Radiological Department of the Johannesburg General Hospital, for the $x$-ray plates of the specimens.

\section{BIBLIOGRAPHY}

Baker, J. R. (1946). Quart. J. micr. Sci., 87, 441.

Brody, H. (1943). Arch. Path., Chicago, 35, 744.

Cain, A. J. (1950). Biol. Rev., 25, 73.

Corper, H. J., and Freed, H. (1922). J. Amer. med. Ass., 79, 1739. Daniel, J. W., Frazer, A. C., French, J. M., and Sammons, H. G. (1953). Biochem. J., 54, xxxvii.

Donnelly, L. C., and Hecht, B. P. (1952). Amer. J. clin. Path., 22, 449. Fienberg, J. (1953). Ibid., 23, 413

Felton, W. L. (1952). Lab. Invest., 1, 364.

(1953). J. thorac. Surg., 25, 530.

Fortner, A. C., and Miles, J.S. (1950). Arch. Path., Chicago, $49,447$. Gomori, G. (1952). Microscopic Histochemistry, University of Chicago Press.

Graef, I. (1935). Amer. J. Path., 11, 862.

- (1939). Arch. Path., Chicago, 28, 613.

Guieysse-Pellissier, A. (1920). C.R. Soc. Biol., Paris, 83, 809.

Hastings, E. V. (1950). Arch. Path., Chicago, 49, 453.

Ikeda, K. (1937). Ibid., 23, 470.

Jacob, O., and Fauré-Fremiet (1917). Rev. Chir., Paris, 54, 221.

Jampolis, R. W., McDonald, J. R., and Clagett, O. T. (1953). Int Abstr., 97, 105.

Laughlen, G. F. (1925). Amer. J. Path., 1, 407.

Lukens, R. M. (1922). J. Amer. med. Ass., 78, 274.

Moran, T. J. (1953). Arch. Path., Chicago, 55, 286.

Pearse, A. G. E. (1953). Histochemistry-Theoretical and Applied. Churchill, London.

Pinkerton, H. (1927). Amer. J. Dis. Child., 33, 259. (1928). Arch. Path., Chicago, 5, 380.

- and Moragues, V. (1940). Ibid., 29, 691

Rosenberg, A. (1885). Berl. klin. Wschr., 22, 449.

Rubin, I. C. (1939). Radiology, 33, 350

Sabin, F. R., Doan, C. A., and Forkner, C. E. (1930), J. exp. Med., 52, Suppl. 3 .

Sicard, J. A., and Forestier, J. (1922). Bull. Soc. méd. Hôp. Paris, 46, 463 .

Storrs, R. P., McDonald, J. R., and Good, C. Allen (1949). J. thorac. Surg., 18, 561.

Stryker, W. A. (1941). Arch. Path., Chicago, 31, 670.

Waters, C. A. Bayne-Jones, S., and Rowntree, L. G. (1917). Arch. intern. Med., 19, 538.

Whitwell, F. (1952). Thorax, 7, 213

Young, A. M., Applebaum, H. S., and Wasserman, P. B. (1939). J. Amer. med. Ass., 112, 2406. 